\title{
Practice and Research of "Traditional Photography Techniques" Teaching in the Digital Age
}

\author{
Min Peng \\ Xi'an University of Technology \\ Xi'an, China
}

\begin{abstract}
With the rapid development of digital technology, traditional photographic printing process faces a great challenge in its development because of its cumbersome process and expensive material, but its image still has very high creativity, so students can study a variety of traditional crafts to set up their photographic aesthetics and viewing modes from material, media and technology, and to experience the charm and value of photos.
\end{abstract}

Keywords - three-dimensional photography; informatization; cultural relics protection

\section{INTRODUCTION}

This course is designed to make students master the basic theory of Traditional photography techniques, establish a solid technical foundation for practice, better serve the photography art, and cultivate students' aesthetic ability and innovation ability. The course has its great significance for cultivation of creative high-quality talent.

\section{OVERVIEW OF "TRADITIONAL PHOTOGRAPHY TECHNIQUES" TEACHING}

The course of "Traditional photography techniques" combines technology and art and has strong practice. Practical teaching is an important part of photography course, which can reflect the practical ability and innovation ability of students. Today, digital technology is developed and replicas is inundant, the research on Traditional photography techniques will find and open a new expression way and artistic inspiration for contemporary. For higher photography education, comprehension and mastery of Traditional photography techniques is a part of spiritual heritage of the photographic culture. The Central Academy of Fine Arts, the Hubei Academy of Fine Arts and other major colleges and universities all have the related courses of Traditional photography techniques. The relevant courses set in the colleges and universities make more students understand and master the quintessence of the traditional photographic printing process, and promote the inheritance and development of traditional photographic printing process. This course is mainly to make students develop the new way of thinking, study the language of photography, and understand the importance of media materials.

Traditional photography techniques include Antppy Type:

This paper is the special scientific research project of Shaanxi Provincial Education Department, project number: 16JK1530. it can be used to get different colors through different flower juice, with low brightness and purity, as shown in "Fig. 1"; Cyanotype: it can used to durably preserve blue, and to show different colors through color mixing, as shown in "Fig. 2"; Albumen print: it can be used to produce clear and fine photos, but the photo easily changes its color after oxidation, as shown in "Fig. 3"; Kallitype: the picture produced by it has a strong performance; Wet Plate Collodion: the picture produced by it has a color of ancient vicissitudes, with strong sense of history and strong nostalgic atmosphere, and the picture is fine and delicate; Gum Bichromate: it can free choose the a variety of watercolor for superposition, to produce the picture of rich colors, and the picture is more similar with the impressionist painting style, and other different printing processes.

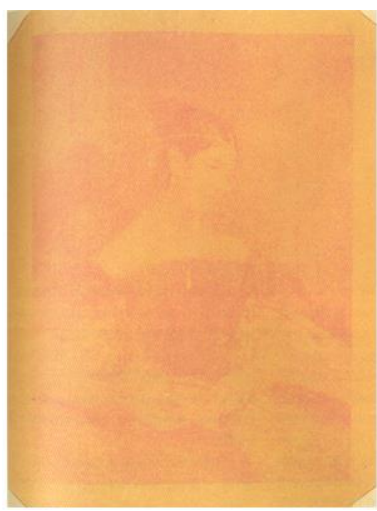

Fig. 1. No.10 Works by Antppy Type

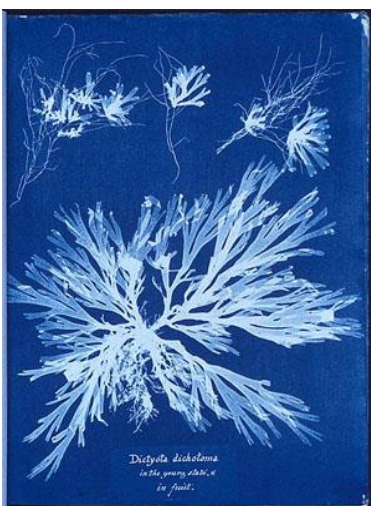

Fig. 2. The picture by Cyanotype/ Anna Atkins. 


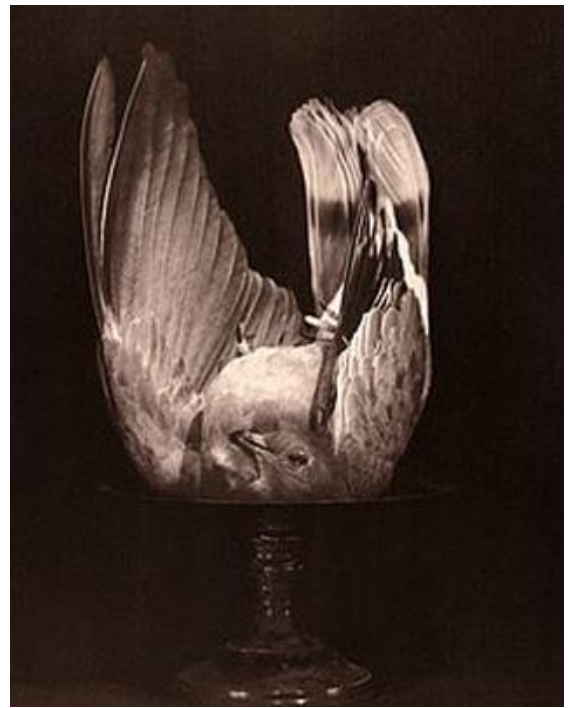

Fig. 3. The picture of aigret / Currie/ John Herschel.

In the course, students can study the development and innovation of traditional photography techniques, and further understand the visual effects and characteristics of the traditional photographic printing process, find and open a new expression way and artistic inspiration for contemporary art. In the experimental process, students mainly master the principles and formula of Cyanotype, such as: the attributes of various drugs, sensitizer formula, drug storage methods; etc; master the performance, principles and use of commonly used instrument, such as: printing-down machine, air dryer, etc.; master the main process of negative film production and output, such as image acquisition, image conversion, image processing, negative output; master the production process of Cyanotype, such as spreading liquid drug - exposure - bathing and developing; and mater the carrier selection for representation of image, such as: paper, cloth and so on.

\section{The APPLICATION AND PRACTICE OF "TRADITIONAL PHOTOGRAPHY TECHNIQUES" TEACHING}

\section{A. Convenience in the Digital Age}

As one of the prerequisites for making a traditional photographic printing process, we need have a negative film with the same size as the final photo. ${ }^{[1]}$ Negative film is the photographic plate we usually talk about. Traditional production of negative film is completed in the dark room, for example, when we shoot with a $35 \mathrm{~mm}$-film camera, the size of each negative film is only $24 \mathrm{~mm} * 36 \mathrm{~mm}$; if you need enlarge the existing negative, you must make a series of process in a dark room to enlarge and copy a negative. For example, we can use Kodak SO-132 under a safety light in a darkroom to enlarge the small negative and then use the standard film developer to make it developed and fixed, so we can get the enlarged negative we need. In the past, the production of negative film is characterized by cumbersome process, low efficiency, long time, low precision, and large human and material resources. But today in the digital age, the development of printers and other technologies provides a great convenience for making traditional photographic printing process, and we can scan the film with a negative film scanner and use the digital image processing software in a computer to create a enlarged digital negative, and then print it out, so the digital copy of film is achieved, which not only improves the quality of works but also reduces the production costs and processes, and improves work efficiency.

\section{B. The Full Integration of Theory and Practice}

In the theoretical teaching at the earlier stage, we can show the original works of various processes to students, so that students experience the charm of different processes. In the course of experiment, we should emphasize students' ability of independent operation. Through the study of experimental course, students can master the principle and formula of Cyanotype and know well the properties and preparation of drugs, students combine with hand-making and coating to master the production process of Cyanotype, and further understand the production and output of negative, the mode of image exposure and the selection of carrier, so that student will know each traditional photography technique has very clear and rigorous production methods and standards. Through the experiment, students will master the coating of picture, the exposure and development by using printing-down machine.

\section{Creativity of Practice Teaching}

As the humidity, temperature, and man-made photosensitive agent thickness is different in each process, each finished works is unique. In the practice teaching is divided into two parts, one part is to use the physical projection to make imaging on the paper spread with photosensitive agent, and the camera is not needed for taking picture, as shown in "Fig. 4"; the other part is to take picture of optional theme, for which each student must propose their own shooting plan at the earlier stage (including shooting content, shooting way, selected material, size, sketch), and then select photos for transfer printing and production at the later stage, as shown in "Fig. 5". Two different ways can make students have a new experience for image, to get the image by a variety of ways but not just by shooting.

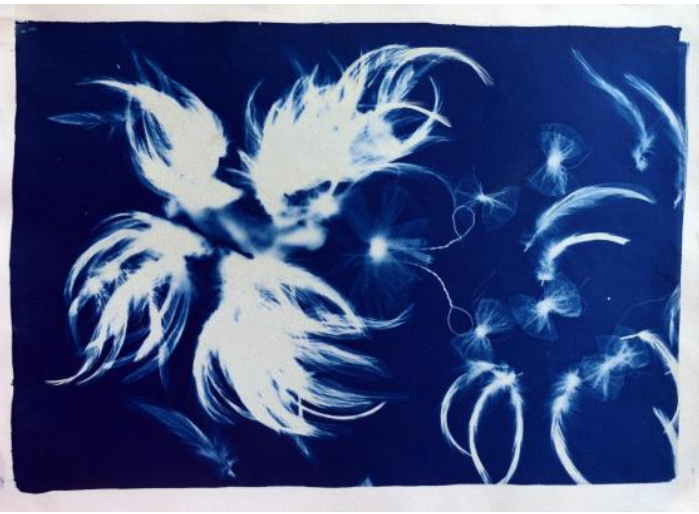

Fig. 4. Student's cyanotype rayograph works. 


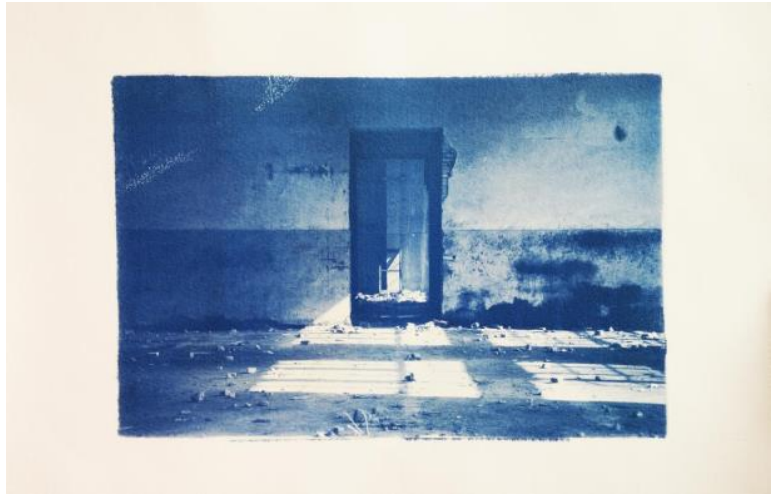

Fig. 5. Student's shooting works.

\section{Hold the Course Exhibition and Organize Students to Participate Actively}

Hold the course exhibition to mobilize the enthusiasm of students and to promote the in-depth exchanges between teachers and students, so as to continuously improve the quality of course teaching and increase students' confidence, "Fig. 6" is for exhibition site, "Fig. 7" is for photo of teachers and students in the exhibition. At the same time, students are required to participate in the competition for full exercise.

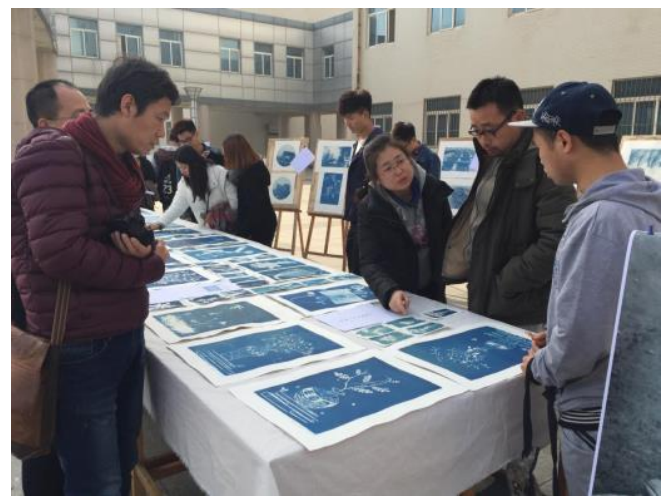

Fig. 6. Exhibition site.

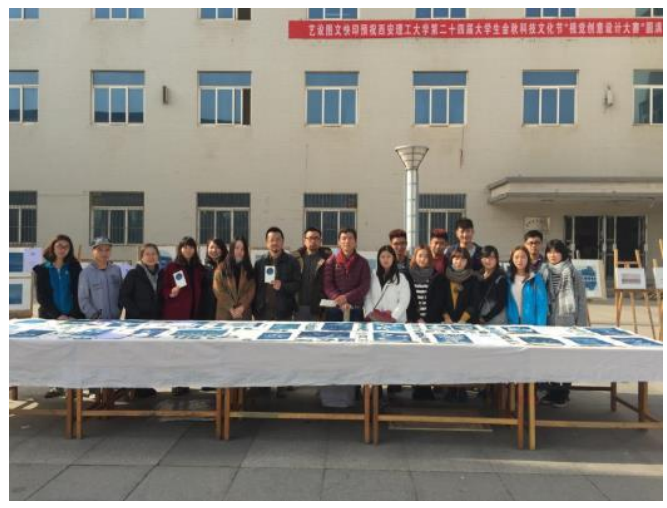

Fig. 7. Photo of teachers and students.

\section{THE IMPORTANCE OF "TRADITIONAL PHOTOGRAPHY TEChNiQues" Course IN THE DigITAL Age}

As a traditional process of human civilization, traditional photographic printing process should not be missed because of national boundaries. In the ever-changing and dazzling technology development, it is important to carry forward and understanding the traditional photographic printing process and to preserve the origin of photography as we advocate preserving the diversity of species and culture.

The application of different photographic printing techniques will bring us a visual change in photography, while it will make the works unique, full of rusticity and warmth due to hand-made way." ${ }^{[3]}$ Each photographic printing technique has its unique visual expression, and today pictures are inundant, the adoption of traditional photographic printing process as a media to carry the image of modern concept, has the promotion of image, and the traditional images make people have a new view and recognition of the pictures. Therefore, if we combine the photography and the traditional photographic printing techniques, we will create more unique works, so that we can more freely express the idea of images, and finally we can combine with the traditional photographic printing process to show the only visual image of the works.

\section{A. The Uniqueness of Traditional Photographic Printing Process}

The digital photography comes into being because it is convenient, intelligent, repeatable and easy to modify and makes it quite easy for the collection and production of images. Of course, the copy of photography is taken as the characteristics of photography, while traditional photographic printing process is hand-made, and due to drug materials, test environment, light source environment and other variable factors, the hand-made works that made by the same technique often show different texture and color, etc. so each works performed by the traditional photographic printing process is a unique and unrepeatable original of photography. The original of photography refers to the original of works that are photographed and subsequently made personally by photographers and photographic artists, or completed by the production studio under the personal instruction of the artists and according to the artists' requirements. ${ }^{[4]}$ This is consistent with the individuality and subjectivity in photography. The combination of photography and traditional photographic printing process can make the image works of unique charm.

\section{B. The Historic Significance of Traditional Photographic Printing Process}

Traditional photographic printing process is the most ancient and original process in the development of photography, and it has experienced more than 100 years of development and improvement, has and receives more than 10 kinds of technology. The historic significance of traditional photographic printing process not only means a long history, more a cultural symbol. In the modern image creation, traditional culture is in an indispensable position. With the improvement of people's life quality and aesthetic value, people have more and more enthusiasm of the traditional 
photographic printing process, and pay more attention to further creation of the works. In the contemporary art development, whether the creative intention and expression way of the works meet people's spiritual demand, mainly is reflected by the metaphor and expression mode of the works. Traditional photographic printing process has a unique expression mode and profound cultural background, which takes a very important part in the history of photographic culture.

\section{The Performance of Traditional Photographic Printing Process}

The traditional photographic printing process has a unique visual expression, but not all images are suitable for the traditional photographic printing process. In the creation of works and for the performance of works, we must select the appropriate way of expression according to the creation purpose and content of works, that is, the creation subject of photography and the presentation mode should be in a high consistency. If the content presented by the works is a group of very modern and concise glass-wall buildings, the performance of works by Cyanotype will give a wrong feeling.

\section{CONCLUSION}

Today, the digital technology is developed and the replicas are inundant, the traditional photography process brings people a puzzled, full of surprises and opportunities and innovative creation process and the unexpected artistic effect. Students can use modern photographic mode in the traditional craftworks course, under the help of traditional material medium, to improve their traditional photography skills and creative skills, and apply their modern innovation awareness to make a new orientation and interpretation of the traditional photographic printing process, and build a different way of expression. Different photographic printing process brings audiences the visual change in photography and makes the works more modest and rustic due to the hand-made modem, which is a spiritual return, and it will open a broader creative space for students.

\section{REFERENCES}

[1] Christopher-Buddha-James. American Professional Tutorial of Photography Picture Production Process [M]. Shanghai People's Publishing House, 2006,06

[2] M.Lanford (UK). Advanced Photography Tutorial [M]. China Photography Press, 1999,08

[3] Anna. H.Hoy. Canon of Photography [M]. China Photography Press, 2007,09

[4] Edited by China Academy of Fine Arts. Original 100 [M]. National Best Publishing House, 2011,08. 